\title{
COMPORTAMENTO DA CAJAZEIRA ENXERTADA SOBRE UMBUZEIRO EM PACAJUS-CE ${ }^{1}$
}

\author{
FRANCISCO XAVIER DE SOUZA² \& ERVINO BLEICHER ${ }^{3}$
}

\begin{abstract}
RESUMO - A cajazeira é uma fruteira da família Anacardiaceae, explorada extrativamente, cujos frutos são nuculânios amarelos, de sabor agridoce, perfumados, ricos em carotenóides, açúcares, vitaminas A e C, denominados de taperebá, cajá-mirim ou cajá e muito utilizados na alimentação humana. Os problemas mais limitantes ao cultivo da cajazeira são a inexistência de clones recomendados para cultivo comercial e o elevado porte da planta. A cajazeira enxertada sobre umbuzeiro apresenta compatibilidade e afinidade entre as partes enxertadas e pouco interfere na forma de crescimento da planta, que é muito semelhante à de planta oriunda de semente, ou seja, tendência em formar caule de haste única e copa alta. A cultura ainda exige estudos sobre as modalidades e épocas de realização das podas para o controle do crescimento da planta e formação de copas que se enquadrem dentro de modelos de exploração intensiva.
\end{abstract}

Termos para indexação: taperebá, cajá, poda, clone, Spondias mombin L.

\section{BEHAVIOUR OF HOG PLUM GRAFTED OVER UMBU IN PACAJUS REGION IN CEARÁ STATE, BRAZIL}

ABSTRACT-Spondias mombin is an Anacardeaceae fruit tree family, widely exploited with drupe yellow sour-sweet taste, highly contents of carotenoid, sugars and vitamins A and C. It is know under several regional names such as hog plum or yellow mombin and is commonly used as a human food source. The main constraints of cropping this species are the lack of uniform recomended clonal genotype and the high height of the plant. The Spondias mombin can be grafted over S. tuberosa showing compatibility and good interaction between both grafting parts. But it doesn't have interference on top plant growth. The top plant growth is similar to that observed by seed propagated plant, thus it tends toward growing by one single trunk and high height. Nevertheless, the control of tree grow and shaping its canopy into exploitation models suitable for intensive cropping still needs further studies as much as to pruning practices and time.

Index terms: Yellow mombin, pruning, clone, Spondias mombin L.

A cajazeira (Spondias mombin L.) pertence à família Anacardiaceae, à qual também pertencem o cajueiro, a mangueira e o umbuzeiro. A planta é uma árvore frutífera perene, de porte alto, lenhosa, de folhas caducas, tronco revestido por casca grossa e rugosa (Lorenzi, 1992), que esgalha e ramifica na parte terminal, conferindo um porte alto à planta. A copa é ampla, vistosa e imponente quando em fase de floração e frutificação.

O centro de diversidade da espécie é a Amazônia Ocidental e a Mata Atlântica (Mitchell \& Daly, 1995), estando disseminada em toda a América tropical (Airy Shaw \& Forman, 1967; Leon \& Shaw, 1990). No Brasil, a cajazeira está dispersa de forma espontânea ou subespontânea em matas, campos de pastagens e em pomares domésticos dos Estados do Norte e Nordeste, sendo considerada espécie em domesticação (Souza, 2000). Os frutos são nuculânios perfumados com mesocarpo carnoso, amarelo, de sabor agridoce, contendo carotenóides, açúcares, vitaminas A e C (Barroso et al., 1999), são denominados de taperebá, cajámirim ou cajá e são muito utilizados na confecção de polpas, sucos, picolés, sorvetes, néctares e geléias de excelente qualidade e valor comercial. A madeira é utilizada em marcenaria; a casca, os ramos, as folhas e as flores possuem propriedades fitoterápicas (Sacramento \& Souza, 2000).

Os problemas mais limitantes ao cultivo da cajazeira são a inexistência de clones recomendados para cultivo comercial e o elevado porte da planta. Porém, segundo Janick (1968), o crescimento das plantas pode ser modificado por meio da poda (Souza, 1985, Simão, 1998), da enxertia e pela aplicação de reguladores de crescimento.

Neste trabalho, são apresentados os resultados das características de crescimento, efeito do porta-enxerto, da poda e do comportamento da cajazeira enxertada sobre umbuzeiro, nas condições edafoclimáticas de Pacajus-CE, obtidos no período de abril de 1997 a abril de 2001.

O plantio foi realizado em sistema quadrangular, no espaçamento de $5 \mathrm{~m}$ x $5 \mathrm{~m}$, em abril de 1997, com mudas de cajazeira clonadas por enxertia sobre porta-enxertos de umbuzeiro. Os porta-enxertos foram oriundos de sementes de um umbuzeiro de Cuité-PB e os garfos retirados de uma cajazeira de Itaitinga-CE. As mudas foram plantadas com idade de 115 dias após a enxertia, em covas de 0,4 m x 0,4 m x
0,4 m, em solo tipo Areia Quartzosa distrófica, no Campo Experimental de Pacajus-CE.

As covas foram adubadas em fundação, duas semanas antes do plantio, com 10 litros de esterco bovino, $100 \mathrm{~g}$ de calcário dolomítico (PRNT 80\%), $400 \mathrm{~g}$ de superfosfato simples e $40 \mathrm{~g}$ de FTE BR-12.

Nas adubações em cobertura, realizadas em 1998, aplicaram-se por planta, $120 \mathrm{~g}$ de uréia e $100 \mathrm{~g}$ de cloreto de potássio, parcelados em três vezes e, de uma única vez, 10 litros de esterco bovino e 20 litros de resíduos de folhas de carnaúba (bagana) por planta. Em 1999 e em 2000, aplicaram-se $178 \mathrm{~g}$ de uréia, $134 \mathrm{~g}$ de superfosfato simples e $50 \mathrm{~g}$ de FTE BR 12, parcelados em duas vezes.

As plantas foram irrigadas por microaspersão, somente no período de abril a novembro de 1997 com cerca de 15 litros de água por planta a intervalos de 15 dias. Em 1999, no período de outubro a novembro, realizaram-se irrigações semanais, aplicando-se 50 litros de água por planta.

No início, as observações e medições foram realizadas em 28 plantas de cajazeira clonadas por enxertia, sendo sete plantas enxertadas por borbulhia, onze por garfagem em fenda lateral e nove por garfagem em fenda cheia. Porém, em razão da morte de quatro plantas, as observações finais foram realizadas em apenas 24 plantas.

As variáveis observadas foram altura de planta, perímetro de caule acima e abaixo do ponto de enxertia, cicatrização e afinidade das partes enxertadas, formato da copa, resposta às podas, emissão de flores e frutos, e ocorrência de pragas e doenças.

As podas foram realizadas com serras e tesouras, quando as plantas estavam na fase fenológica de repouso vegetativo, totalmente desfolhadas e com as gemas em divisão celular e intumescidas. A primeira poda foi drástica e realizada em outubro de 1999, quando se podaram os ramos grandes e vigorosos para reduzir o porte das plantas; a segunda poda foi realizada em setembro de 2000, quando as plantas foram divididas em três grupos: no grupo 1, composto de seis plantas, podaram-se apenas os ponteiros, aparando-se cerca de $20 \mathrm{~cm}$ dos ramos apicais; no grupo 2, também composto de seis plantas, realizou-se uma poda drástica, serrando-se todos os ramos pela metade; e no grupo 3, composto de doze plantas não se realizou poda. As partes cortadas das plantas foram tratadas com uma calda à base de cobre. 
Antes do plantio, as mudas estavam vigorosas e com a região de enxertia bem cicatrizada. Em cultivo, logo após o plantio, observouse um desenvolvimento vegetativo normal (Figura 1a), seguido pela fase de repouso vegetativo, quando as plantas perderam todas as folhas (Figura 1b), voltando a iniciar a emissão de brotações em setembro de 1997. Na época de produção da cajazeira safra de 1997/98, do primeiro ano de cultivo, seis plantas floresceram e apenas três frutificaram. Essa precocidade, provavelmente, foi devida às alterações bioquímicas e à condição fisiológica dos garfos, cujas gemas vegetativas tinham se diferenciado, ainda na planta-matriz, em gemas reprodutivas e não foram alteradas pela enxertia. As plantas de cajazeira enxertadas apresentaram altas taxas de crescimento durante as fases de floração e de frutificação, com cerca de 120 dias, cujas diferentes fases de uma mesma planta podem ser observadas na Figura 2 ( $a, b$ e c).

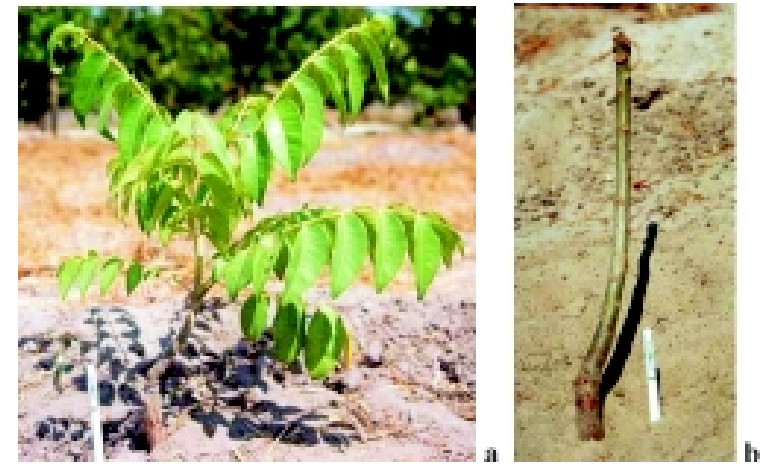

FIGURA 1 - Clone de cajazeira logo após o plantio em fase de desenvolvimento vegetativo (a) e em repouso vegetativo (b). PacajusCE. 1997.

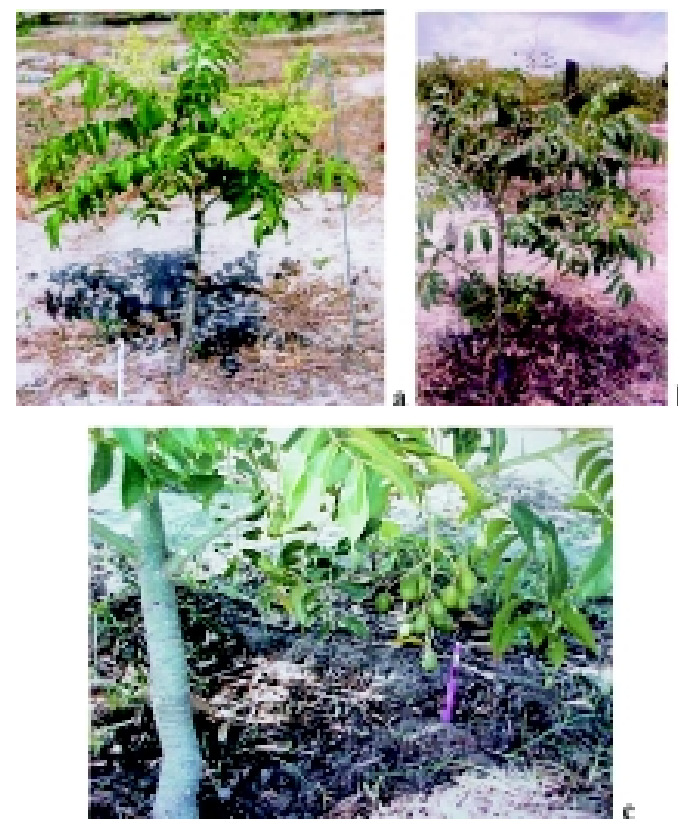

FIGURA 2 - Clone de cajazeira: a) em fase de floração; b) floraçãofrutificação; e c) em frutificação. Pacajus-CE. 1998.

Na safra de 1998/99, apenas três plantas floresceram, mas não produziram. Nesse período, as plantas tiveram um rápido crescimento vertical, com troncos de haste única e tendência de formarem copas altas que se esgalham na parte terminal, como nas plantas propagadas por sementes, indicando que a enxertia de cajazeira sobre umbuzeiro não reduz o porte das plantas, havendo, portanto, necessidade de realização da poda de formação, durante o primeiro ano de cultivo, para obtenção de plantas com porte reduzido e copas esgalhadas, conforme Souza (1985) e Simão (1998).

Em todas as épocas de crescimento das plantas (que, via de regra, ocorre no período de setembro a junho de cada ano, quando as gemas brotam e se diferenciam em folhas e flores e até a senescência das folhas, quando os ramos ficam caducos), sempre ocorreu uma alta taxa de crescimento das plantas com emissão de ramos longos e vigorosos, principalmente nas plantas de haste única, nas quais a copa não esgalhou e o crescimento vertical foi dominante.

Pela Tabela 1, percebe-se que as plantas, independentemente do método de enxertia, tiveram um rápido desenvolvimento e crescimento com predominância de caule com haste única, que esgalha na parte terminal, ou seja, seguiram a tendência das plantas propagadas por sementes, sendo, portanto, uma característica da espécie. Observa-se, ainda, que, até os 16 meses de idade, as plantas enxertadas por borbulhia tinham as maiores médias de altura e perímetro de caule, sendo superadas pelas plantas enxertadas por garfagem nas avaliações posteriores.

TABELA 1 - Médias de altura de planta, perímetro de caule e aspecto do formato da copa de clones de cajazeira em cultivo. PacajusCE. 2001 .

\begin{tabular}{|c|c|c|c|c|c|c|}
\hline \multirow[t]{2}{*}{ Métodos Enxertia } & \multirow{2}{*}{$\begin{array}{c}\text { Altura } \\
\text { planta }(\mathrm{cm})\end{array}$} & \multicolumn{2}{|c|}{ Perímetro do caule $(\mathrm{cm})$} & \multicolumn{2}{|c|}{$\begin{array}{l}\mathrm{N}^{0} \text { plantas com copa no } \\
\text { formato }\end{array}$} & \multirow{2}{*}{$\begin{array}{l}\mathrm{N}^{0} \text { plantas } \\
\text { observadas }\end{array}$} \\
\hline & & Porta-enxerto & Enxerto & Haste única & Esgalhada & \\
\hline \multicolumn{7}{|c|}{ Plantas com 16 meses de idade - Resultados obtidos em agosto de 1998} \\
\hline Borbulhia & 55,6 & 10,0 & 7,5 & 4,0 & 3,0 & 7,0 \\
\hline Fenda lateral & 28,2 & 10,0 & 7,2 & 9,0 & 2,0 & 11,0 \\
\hline Fenda cheia & 35,1 & 9,1 & 7,0 & 8,0 & 1,0 & 9,0 \\
\hline \multicolumn{7}{|c|}{ Plantas com 21 meses de idade - Resultados obtidos em janeiro de1999 } \\
\hline Borbulhia & 100,0 & 12,5 & 10,6 & 1,0 & 6,0 & 7,0 \\
\hline Fenda lateral & 120,8 & 13,0 & 11,8 & 4,0 & 5,0 & 9,0 \\
\hline Fenda cheia & 140,7 & 15,8 & 11,6 & 4,0 & 5,0 & 9,0 \\
\hline \multicolumn{7}{|c|}{ Plantas com 30 meses de idade - Resultados obtidos em outubro de 1999} \\
\hline Borbulhia & 170,0 & 22,0 & - & 1,0 & 6,0 & 7,0 \\
\hline Fenda lateral & 213,0 & 23,0 & - & 4,0 & 5,0 & 9,0 \\
\hline Fenda cheia & 189,0 & 24,0 & - & 4,0 & 5,0 & 9,0 \\
\hline \multicolumn{7}{|c|}{ Plantas com 46 meses de idade - Resultados obtidos em fevereiro de 2001} \\
\hline Borbulhia & 187,1 & 25,3 & 24,3 & 0,0 & 7,0 & 7,0 \\
\hline Fenda lateral & 248,3 & 30,7 & 31,7 & 0,0 & 9,0 & 9,0 \\
\hline Fenda cheia & 232,5 & 28,9 & 28,4 & 0,0 & 8,0 & 8,0 \\
\hline
\end{tabular}

Em outubro de 1999, quando as plantas tinham 30 meses de idade e encontravam-se totalmente caducas, ou seja, na fase de repouso vegetativo, constataram-se algumas muito vigorosas com altura média variando de 170 a $213 \mathrm{~cm}$, das quais dez tinham caule com haste única (Tabela 1) e a maioria era pouco esgalhada com bifurcação de dois galhos longos e vigorosos (Figura 3a). Devido a essa forma de crescimento, realizou-se uma poda drástica, quando as plantas se encontravam no final da fase de repouso vegetativo, ou seja, com as gemas intumescidas. Após a poda, as plantas apresentaram caules que variaram de $70 \mathrm{~cm}$ a $140 \mathrm{~cm}$ de altura (Figura 3b). Três semanas após a poda, constatou-se o surgimento de muitas brotações em todas as plantas, provavelmente causado pelo desvio de água, nutrientes e substâncias de reserva do sistema radicular para a copa (Janick, 1966). Aos trinta dias após a poda, realizaram-se seleção e raleamento das brotações emitidas, visando à formação de copas com ramos bem distribuídos e esgalhadas (Figura $3 c$ ). As respostas das plantas à poda foi a emissão de ramos vigorosos e alta taxa de crescimento vegetativo (Figura 3c), não emitindo flores na época de produção (dezembro a fevereiro), provavelmente em razão de a poda drástica ter favorecido a emissão de ramos de crescimento (ortotrópicos) em detrimento dos ramos de frutificação. Segundo Janick (1966), após uma intensa poda, ocorre um vigoroso crescimento vegetativo, devido ao fato da poda alterar, radicalmente, o equilíbrio entre o sistema radicular e foliáceo, tendo a poda drástica um efeito de rejuvenescimento.

Em novembro de 2000, após a segunda poda (Figura 4a), constatou-se maior emissão de brotações nas plantas podadas, sendo necessárias, trinta dias após, uma poda de raleamento e seleção das rebrotas para formação de copas esgalhadas. De todas as plantas, apenas uma planta, podada de forma drástica, emitiu flores e, em abril de 2000, tinha um cacho com três frutos.

Pelas avaliações realizadas em fevereiro de 2001, constatou-se em todas as plantas que houve uma alta taxa de crescimento com emissão de ramos longos e vigorosos, resultando em plantas com altura média variando de $187 \mathrm{~cm}$ a $232 \mathrm{~cm}$ (Tabela 1), cujos ramos apenas vege- 


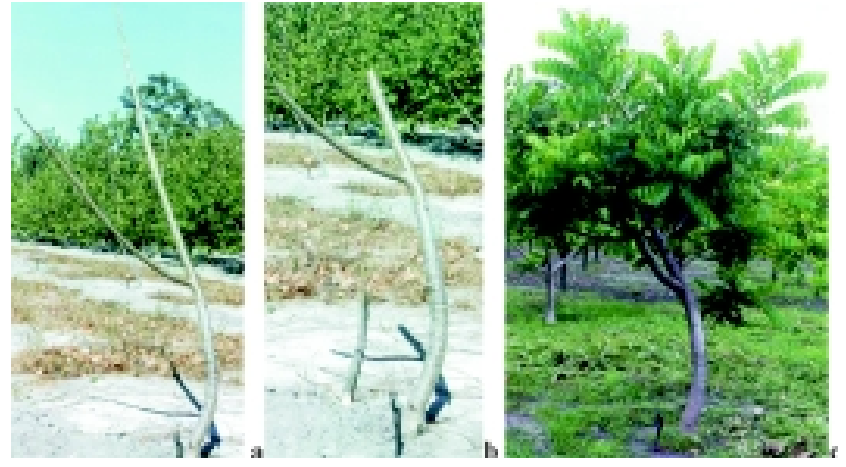

FIGURA 3 - Clone de cajazeira em fase de repouso vegetativo (caduca): a) antes da poda, b) podada drasticamente e c) em plena fase de crescimento vegetativo. Pacajus, CE. 1999.

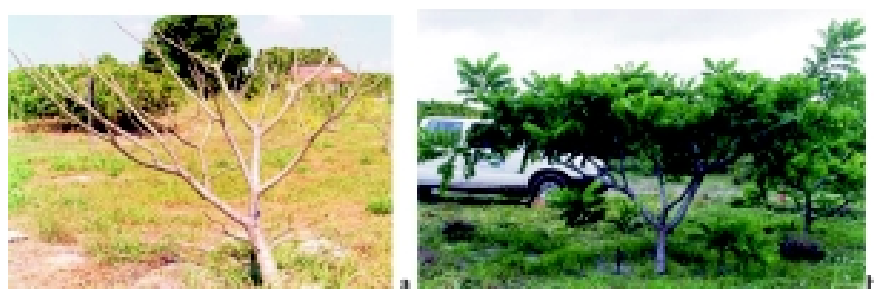

FIGURA 4 - Clone de cajazeira em repouso vegetativo caduca: a) podada os ponteiros; e b) totalmente enfolhada em fase de crescimento vegetativo. Pacajus, CE. 2001.

taram (Figura 4b) e somente uma planta frutificou.

Durante o período de cultivo, foram observadas ocorrências de pulgão, atacando as brotações novas e inflorescências; de saúvas do gênero Atta, mané-magro ou bicho-pau (Stiphra robusta Leitão) e gafanhotos, atacando as folhas; e de cochonilhas, atacando os ramos.

Pelos resultados, constata-se que há compatibilidade e afinidade entre as partes enxertadas do umbuzeiro como porta-enxerto e da cajazeira como enxerto. A cajazeira enxertada sobre umbuzeiro mantém a mesma forma de crescimento da planta oriunda de semente, ou seja, cresce com caule de haste única, formando planta vigorosa com copa alta que esgalha na parte terminal do caule. As plantas de cajazeira enxertadas sobre umbuzeiro perdem a precocidade expressada ainda no primeiro ano de cultivo e respondem à poda, com emissão de ramos de crescimento longos e vigorosos, porém, são necessários estudos para definição de quando e como fazer a poda.

Em virtude da forma de crescimento vertical, com troncos de haste única, e do elevado porte apresentado pelas plantas enxertadas de cajazeira em porta-enxerto de umbuzeiro e pelos resultados obtidos com as podas, conclui-se pela necessidade da continuidade dos estudos sobre as modalidades e épocas de realização das podas para obtenção de plantas com copas que se enquadrem dentro de modelos de exploração intensiva da cultura.

\section{REFERÊNCIASBIBLIOGRÁFICAS}

AIRY SHAW, H.K.; FORMAN, L.L: The genus Spondias L. (Anacardiaceae) in tropical Asia. Kew Bulletin, v. 21, n. 1, p. 1-20. 1967.

BARROSO, G.M., MORIM, M.P., PEIXOTO, A.L., ICHASO, C.L.F. Frutos e sementes: morfologia aplicada à sistemática de dicotiledôneas. Viçosa:Universidade Federal de Viçosa, 1999. 433p.

JANICK, J. Orientação do crescimento da planta. In: JANICK, J. A ciência da horticultura. 2. ed. Rio de Janeiro:Freitas Bastos, 1968. Cap. 7, p. 202-237.

LEON, J.; SHAW, P.E. Spondias: the red mombin and related fruits. In: NAGY, S.; SHAW, P.E.; WARDONSKI, F.W.(Ed.) Fruits of tropical and subtropical origem: composition, properties and uses. Lake Alfred: Florida Science Sourse, 1990. p.117-26.

LORENZI, H. Árvores brasileiras: manual de identificação e cultivo de plantas arbóreas nativas do Brasil. Nova Odessa. Plantarum, 1992. 370p.

MITCHELL, J.D.; DALY, D.C. Revisão das espécies neotropicais de Spondias (Anacardiaceae). In: CONGRESSO NACIONAL DE BOTÂNICA, 46., 1995, São Paulo. Anais... São Paulo: Universidade de São Paulo/SBB, 1995. p. 207.

SOUZA, J.S.I. Poda das plantas frutíferas. 12. ed. São Paulo: Nobel, 1985.224p.

SIMÃO. S. Tratado de fruticultura. Piracicaba:FEALQ, 1998. 760p.

SACRAMENTO, C.K. do.; SOUZA, F.X. de. Cajá (Spondias mombin L.). Jaboticabal:Funep, 2000. 42p. (Série Frutas Nativas, 4). 